\title{
Analyse the disk closed cycle MHD generator performance with the influence of channel characteristics
}

\section{- Le Chi Kien}

Ho Chi Minh city University of Technology and Education

(Manuscript Received on March 12th, 2015, Manuscript Revised April 04th, 2016)

\begin{abstract}
The enthalpy extraction ratio is one of the most significant parameter of a disk closed cycle $M H D$ generator. There are two methods to improve the enthalpy extraction, those are the increase of channel cross-sectional area ratio and the implementation of inlet swirl. In this study, the mechanism of enthalpy extraction improvement has been confirmed by the two-dimensional numerical calculation. As a result, by increasing the channel cross-sectional area ratio of the disk MHD generator, the increase of static pressure and the velocity deceleration can be suppressed

due to the Lorentz force, and it is possible to maintain a high flow velocity inside the channel and a high Hall parameter. The implemention of inlet swirl is possible to maintain a low static pressure inside the channel and the enthalpy extraction ratio rises due to the increase of Hall parameter. In addition, the channel crosssectional area ratio increases due to the swirl implementation, the static pressure is kept low, and the channel inlet flow velocity increases. This also leads to the increase of enthalpy extraction ratio, that is the increase of output power.
\end{abstract}

Keywords: Enthalpy extraction, cross-sectional area ratio, inlet swirl, two-dimensional calculation.

\section{INTRODUCTION}

Disk closed cycle MHD (CCMHD) power generation directly converts the thermal and kinetic energy into the electrical energy by flowing a electrical conduction working fluid in the radial direction into a disk channel which is applied by a magnetic field. Recently, CCMHD generator has revealed experimentally a high enthalpy extraction ratio by using a disk-shaped channel. There are two methods to improve the enthalpy extraction. They are the increase of channel cross-sectional area ratio and the implementation of inlet swirl.

The improvement of enthalpy extraction ratio due to the increase of generator channel cross-sectional area ratio is revealed 
experimentally by using a blowdown equipment and shock tube [1]. It is known that the increase of channel cross-sectional area ratio opposes the velocity deceleration due to strong Lorentz force, and leads to a high flow velocity inside the generator channel. At this time, it puts a low static pressure inside the generator channel and may achieve a high Hall parameter. The improvement of enthalpy extraction is indicated by the quasi one-dimensional calculations [2].

The improvement of enthalpy extraction ratio by the implementation of inlet swirl (swirl flow) is described by experiments using the shock tube, and this has achieved a high enthalpy extraction of over $30 \%$ [3]. The low static pressure inside the channel is preserved due to the inlet swirl, and the maintain of a high Hall parameter is similarly indicated by the quasione-dimensional calculations [4].

The quasi one-dimensional calculation time is short, and this calculation has been used to describe the qualitative trend of the experimental results because it is possible to change many parameters. However in the quasi onedimensional calculation, the boundary layer displacement thickness must be assumed, therefore in recent years, a boundary layer twodimensional calculation has been proposed, but the suitability should be studied because it is clearly that the boundary layer thickness is significantly different with different operational condition $[5,6,7]$. In this study, the mechanism of enthalpy extraction improvement which considers the inlet swirl and the increase of the channel cross-sectional area ratio has been confirmed by the two-dimensional numerical calculation. In addition, this study not only examines the behavior of a boundary layer with different inlet swirl and channel shape but also shows the characteristics of the flow field that has received a strong Lorentz force.

\section{MHD PLASMA AND BASIC EQUATIONS}

In this study, the non-equilibrium plasma using a two-temperature model is described [8]. The following assumptions have been proposed for the plasma of CCMHD generator.

(1) Ignore the displacement current.

(2) Electrical neutral is maintained.

(3) Magnetic Reynolds number is rather small, and the magnetic field is constant.

(4) Influence of ion slip can be ignored.

Furthermore, it is assumed that the following equations are expressed in a cylindrical coordinate system and the uniformity in the circumferential direction $\partial / \partial \theta=0$. Basic equations are composed of non-equilibrium plasma equations and the governing equations in the flow field that describes the working fluid. Symbols used in this study agree with the habitual symbols. The details of calculation method and basic equations are refered in $[6,7]$.

\subsection{Governing equations}

The governing equations of the flow field are written in the forms of very famous compressibility Navier-Stokes equations, and the MHD effect is applied to the energy and momentum equation. The state equations are also used appropriately.

$$
\begin{aligned}
& \frac{d \rho}{d t}=-\rho \nabla \cdot \boldsymbol{u} \\
& \frac{d u_{r}}{d t}=\frac{j_{\theta} B}{\rho}+\frac{u_{\theta}^{2}}{r}-\frac{1}{\rho} \frac{\partial p}{\partial r}+V_{r}
\end{aligned}
$$

\section{Trang 14}


$\frac{d u_{\theta}}{d t}=-\frac{j_{r} B}{\rho}-\frac{u_{r} u_{\theta}}{r}+V_{\theta}$

$\frac{d u_{z}}{d t}=-\frac{1}{\rho} \frac{\partial p}{\partial z}+V_{z}$

$\rho c_{v} \frac{d T}{d t}=-p \nabla \cdot \boldsymbol{u}+\frac{|\boldsymbol{j}|^{2}}{\sigma}+H$

Here, $V$ is viscosity term, and $H$ in energy equation shows the dissipation due to the heat conduction and viscosity.

\subsection{Plasma equations}

Equations describing the plasma consist of ionization equations, generalized Ohm's law equations, and energy equations.

The energy equations ignore the time and spatial gradient, and they are expressed as the algebraic equations by assuming the relaxation time of the electron temperature is much shorter than the relaxation time of the electron number density.

$$
\begin{aligned}
& \frac{d n_{i}^{+}}{d t}=-n_{i}^{+} \nabla \cdot \boldsymbol{u}+\dot{n}_{i}^{+} \\
& j_{r}=\frac{\sigma}{1+\beta^{2}}\left(E_{r}+u_{\theta} B+\beta u_{r} B\right) \\
& j_{\theta}=\frac{\sigma}{1+\beta^{2}}\left(\beta E_{r}+\beta u_{\theta} B-u_{r} B\right) \\
& j_{z}=\sigma E_{z} \\
& \frac{\mid \boldsymbol{j}^{2}}{\sigma}=3 n_{e} m_{e} k\left(T_{e}-T\right) \sum_{j} \frac{v_{j}}{m_{j}}+\sum_{i} \dot{n}_{i}^{+}\left(\frac{3}{2} k T_{e}+\varepsilon_{i}\right)
\end{aligned}
$$

Here, $\beta$ is the Hall parameter, $\sigma$ is the electrical conductivity, $n_{i}^{+}$the ion number density, $\dot{n}_{i}^{+}$is the ion number density that is generated per unit time, $v_{j}$ is the collision frequency between electron and $j$-particle, $\varepsilon_{i}$ is the $i$-particle ionization potential. Maxwell's equations are put together the following two equations by MHD approximation.

$$
\begin{aligned}
& \frac{\partial E_{r}}{\partial z}-\frac{\partial E_{z}}{\partial r}=0 \\
& \frac{1}{r} \frac{\partial}{\partial r}\left(r j_{r}\right)+\frac{\partial j_{z}}{\partial z}=0
\end{aligned}
$$

\subsection{Boundary conditions and analysis method}

The area for numerical analysis is from the throat to the downstream end of the cathode. Physical quantity for the generator symmetric plane $(z=0)$ is assumed to be symmetric, and only the upper surface is analysed. The ionization equation and the governing equation of flow field are solved by using the CIP method [9]. To solve and combine the Maxwell equation and the generalized Ohm's law equation, the potential function $\phi$ is defined and this is solved by using the Galerkin method which is one type of finite element method. The common conditions used for the calculation are shown in Table 1. Outlet boundary is a free outflow condition. Applied

\begin{tabular}{|c|c|c|}
\hline Working gas & & $\mathrm{Ar}+\mathrm{Cs}$ \\
\hline Seed fraction & & $2 \times 10^{-4}$ \\
\hline Wall temperature & {$[\mathrm{K}]$} & 500 \\
\hline \multicolumn{3}{|l|}{ Inlet Boundary Condition } \\
\hline Stagnation temperature & {$[\mathrm{K}]$} & 2000 \\
\hline Electron temperature & {$[\mathrm{K}]$} & 3000 \\
\hline
\end{tabular}
magnetic field uses a magnetic field distribution that has been used in Fuji-1 MHD disk generator [10]. This magnetic field is 4.7 [T] at the inlet and $2.5[\mathrm{~T}]$ at the outlet after applying to downstream and reducing gently.

Table 1. Calculation conditions. 


\section{RESULTS AND DISCUSSION}

\subsection{Influence of channel cross-sectional area} ratio

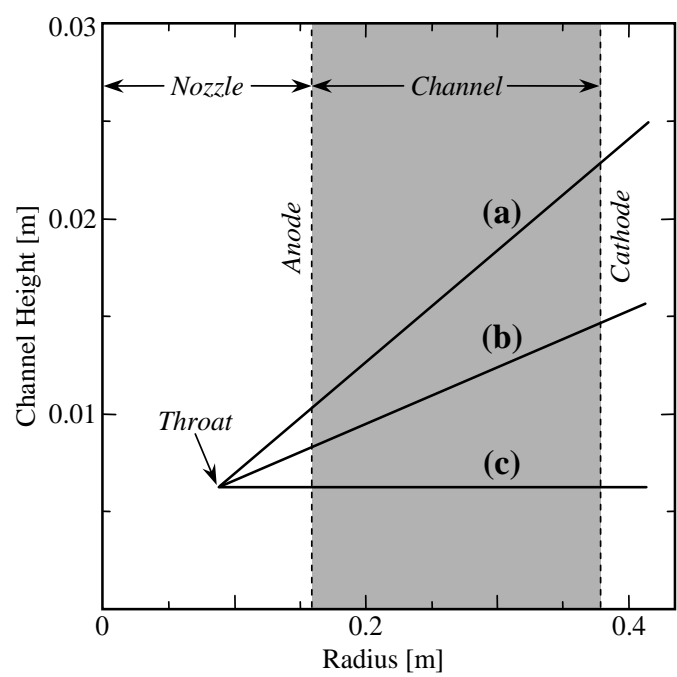

Figure 1. Generator channel height with different cross-sectional area ratios.

In order to investigate the influence of channel cross-sectional area ratio to the enthalpy extraction ratio, the calculation for three different cross-sectional area ratios of disk MHD generator is carried out and shown in Fig. 1. The channel height in this figure is the distance from the wall to the symmetrical plane of the generator. Fig. 1 represents the scale expended in the $z$-direction. The graph (a), (b), (c) is in order of decreasing cross-sectional area ratio of the channel. The channel of the graph (b) has almost the same shape as the channel of MHD device refered in [10]. The stagnation pressure is calculated at $0.60 \mathrm{MPa}$ with each cross-sectional area ratio, and the inlet swirl is calculated at 0 .

Fig. 2 shows dependence of the enthalpy extraction ratio on the load resistance for each cross-sectional area ratio, respectively. The maximum of enthalpy extraction ratio in each cross-sectional area ratio has been achieved by the load resistance of $0.5 \Omega$.

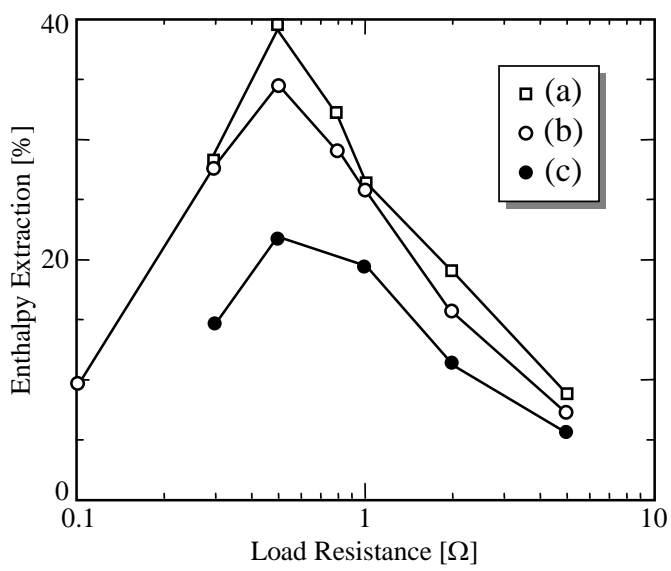

Figure 2. Relationship of enthalpy extraction and load resistance.

The enthalpy extraction ratio increases with the increasing of the cross-sectional area ratio. When comparing the enthalpy extraction of the channel (a) and channel (b), the enthalpy extraction at $0.5 \Omega$ load resistance increases, however, it remains to increase about $1 \%$ at the load resistance which is bigger or smaller than this value and when the cross-sectional area ratio is bigger, the decreasing of the enthalpy extraction which is out of the optimum load resistance is remarkable.

Fig. 3 shows the radial direction distribution of the quantities in the symmetrical plane $(z=0)$ for each cross-sectional area ratio when the maximum output is obtained at the load resistance of $0.5 \Omega$. The static pressure in the generator channel remains low as the channel cross-sectional area ratio increases. As the static pressure is low, the collision frequency between electrons and heavy particles reduces, consequently Hall parameter increases. Moreover in the channel (a), (b) with large crosssectional area ratio, the velocity deceleration of

\section{Trang 16}


working fluid is not sudden as in the channel (c). Thus, as the channel cross-sectional area ratio enlarges, the deceleration of working fluid and the rise of static pressure can be suppressed by the Lorentz force, and the increasing of both the electromotive force $\beta u_{r} B$ and the enthalpy extraction is confirmed when the flow velocity and Hall parameter is high. In addition, with the enlargement of the channel cross-sectional area ratio, the flow velocity at the channel inlet rises, and this leads to a rise of enthalpy extraction ratio.
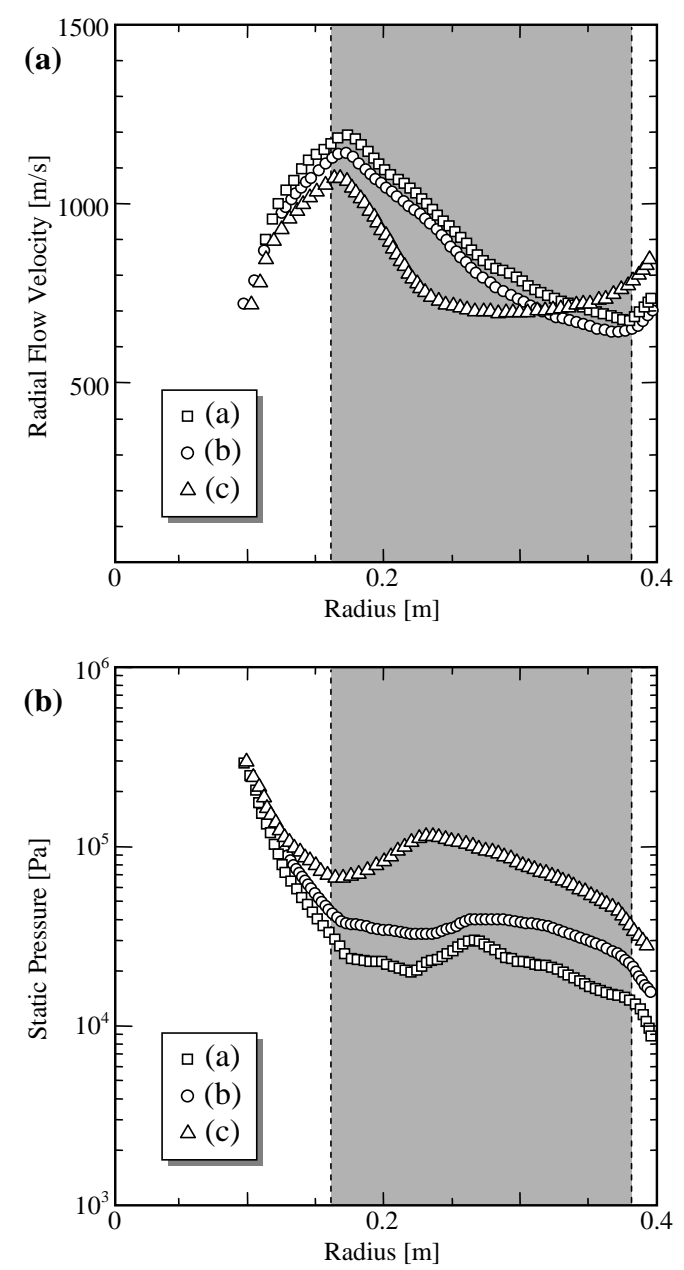

Figure 3. Radial distribution of radial flow velocity and static pressure with different area ratios.
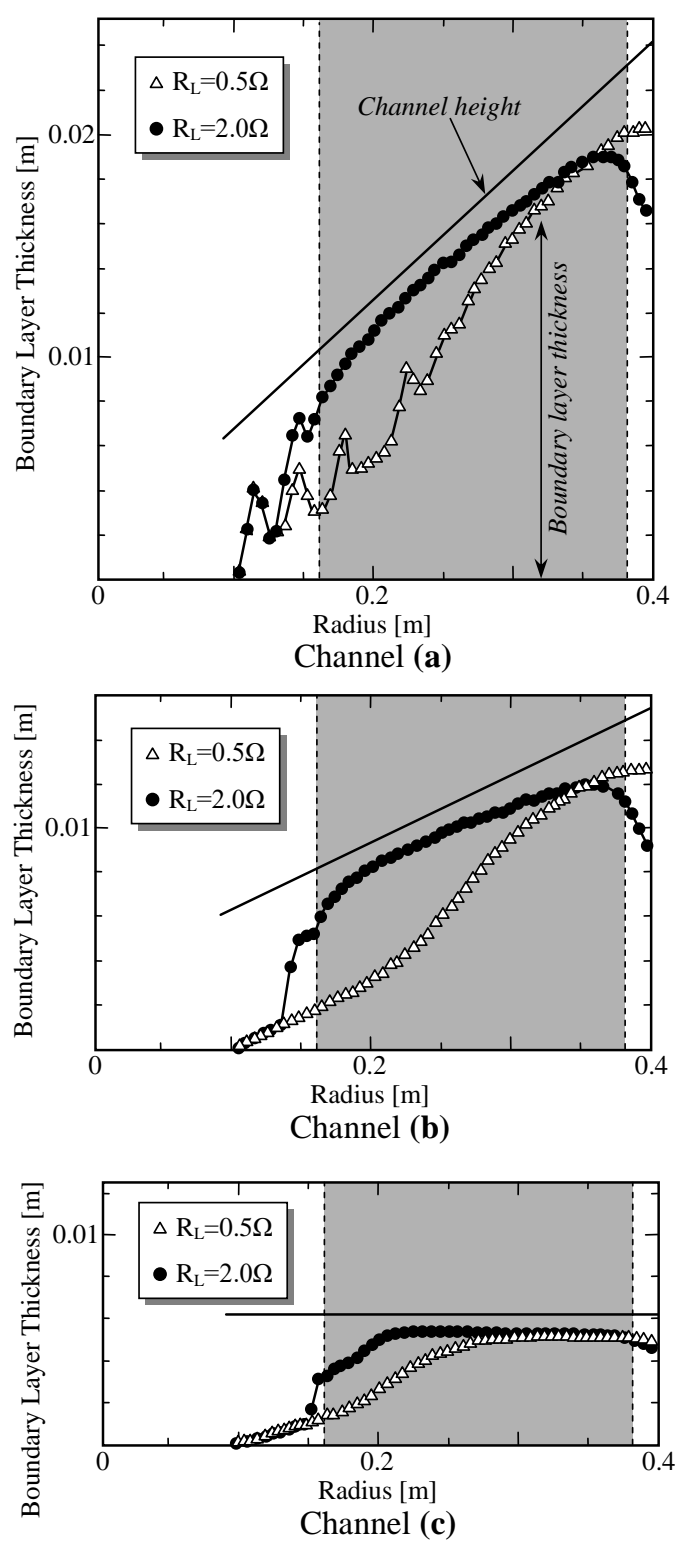

Figure 4. Boundary layer thickness with different cross-sectional area ratios.

Next, the development state of boundary layer in each channel is shown in Fig. 4. In channel (a) particularly, the development of boundary layer is great, and the boundary layer in the channel outlet vicinity almost spreads throughout the channel and it will extend to the nozzle when the load resistance is high. As the 
boundary layer extends greatly to the nozzle, the flow velocity and the Hall parameter in the channel inlet is lower comparing to the case of low load resistance. In contrast, the extent of the boundary layer in the nozzle is small even when the load resistance is high in the channel (c). With the enlargement of the channel crosssectional area, the boundary layer thickness increases that thickness, and the increasing of that thickness is remarkable at a high load resistance. The power output in channel (a), (b) increases significantly in the low load resistance case in which the extent of boundary layer is slight as shown in Fig. 2 comparing to the channel (c). However, when the load resistance is high, the increasing of power output is small but the boundary layer develops greatly and the decrease of the influence which increases the cross-sectional area ratio can be explained.

\subsection{Influence of inlet swirl}

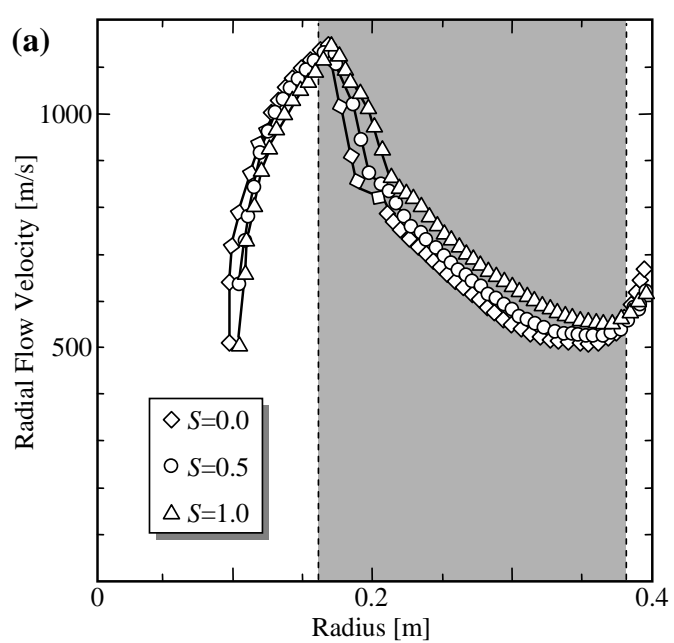

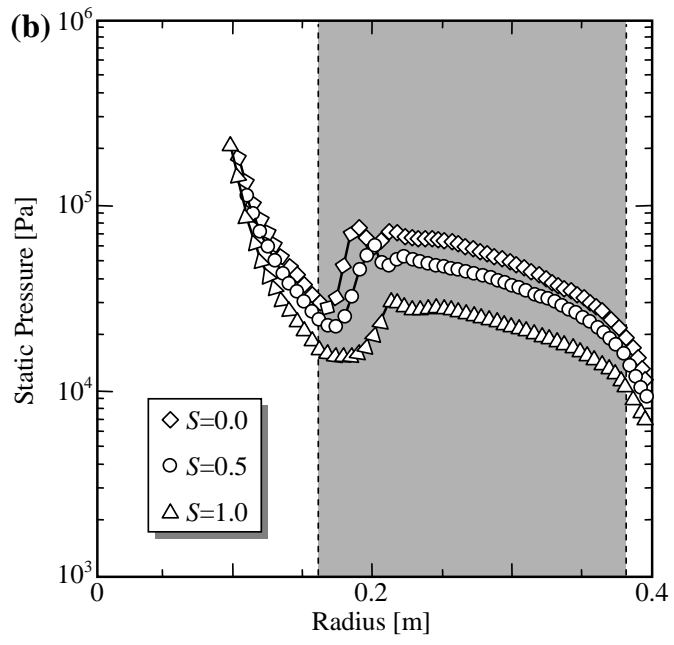
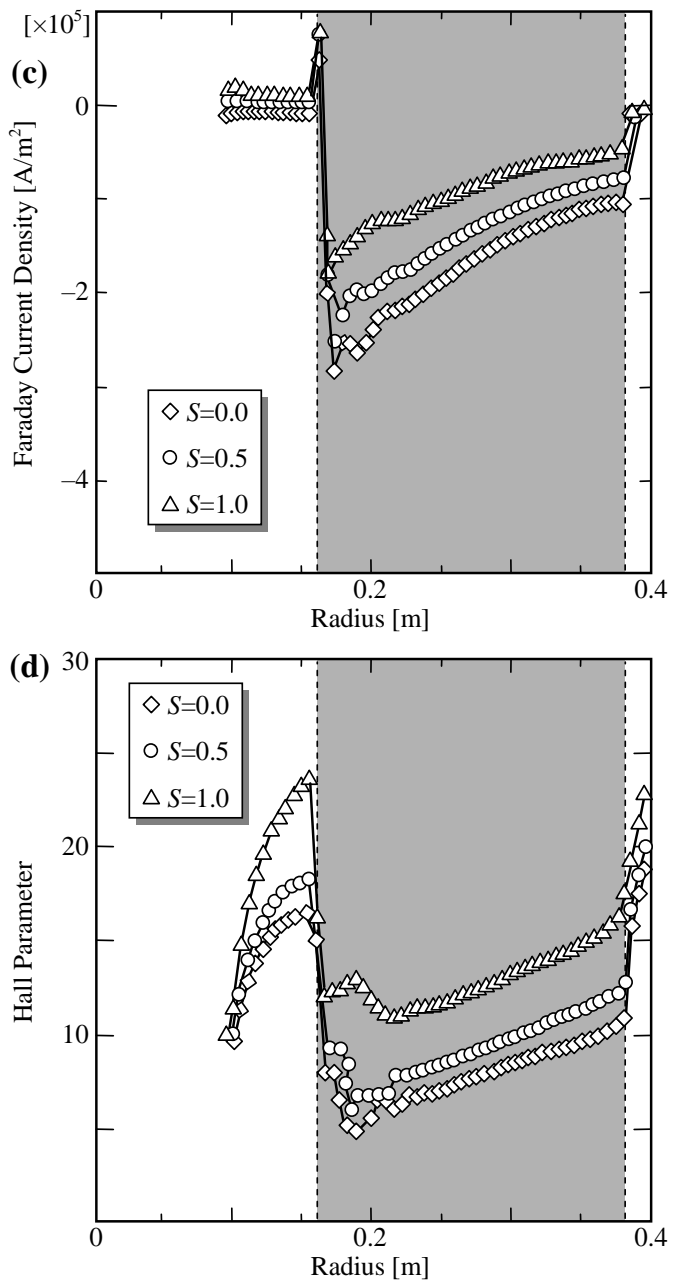

Figure 5. Radial distributions with various inlet swirl. 
Swirl $S$ is defined as the ratio of the radial flow velocity to the circumferential flow velocity (momentum). The swirl calculations were carried out with $S=0,0.5,1.0$ in the throat. Since the Mach number at the throat is fixed at 1.0, the radial flow velocity is small due to the swirl, and the heat input expressing by $\rho u_{r} c_{p} T A$ ( $A$ is throat cross-sectional area) decreases. The calculation used the channel (b) and the stagnation pressure was set to $0.45 \mathrm{MPa}$. Table 2 shows the achieved enthalpy extraction. As the swirl is provided, the heat input declines and then the power output reduces, however, the enthalpy extraction rises.

Table 2. Dendence of power output and enthalpy extraction on inlet swirl.

\begin{tabular}{|c|c|c|c|c|}
\hline \multicolumn{2}{|l|}{ Inlet swirl } & 0.0 & 0.5 & 1.0 \\
\hline Inlet $u_{r}$ & {$[\mathrm{~m} / \mathrm{s}]$} & 721.3 & 675.2 & 510.1 \\
\hline Thermal input & [MW] & 3.75 & 3.3 & 2.65 \\
\hline Power output & [MW] & 1.18 & 1.24 & 1.07 \\
\hline Enthalpy extrac & on $[\%]$ & 31.6 & 37.7 & 40.3 \\
\hline
\end{tabular}

Fig. 5 shows the radial distribution of various quantities in the symmetrical plane. The static pressure distribution is kept low as the swirl is provided. Although the radial flow velocity at the throat is small because of providing a swirl, it is nearly the same value in the channel inlet. This is because there is a difference occuring in the isentropic flow by the swirl, and there is a behavior to change the crosssectional area in the flow direction by providing a swirl [11]. As a result, in the nozzle in which the isentropic flow is nearly the same, a high Mach number can be obtained from the channel inlet, while the static pressure is small and the Hall parameter is large.

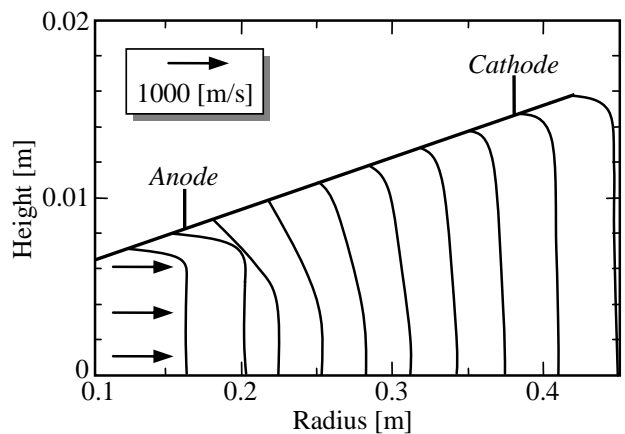

(a) $S=0.0$

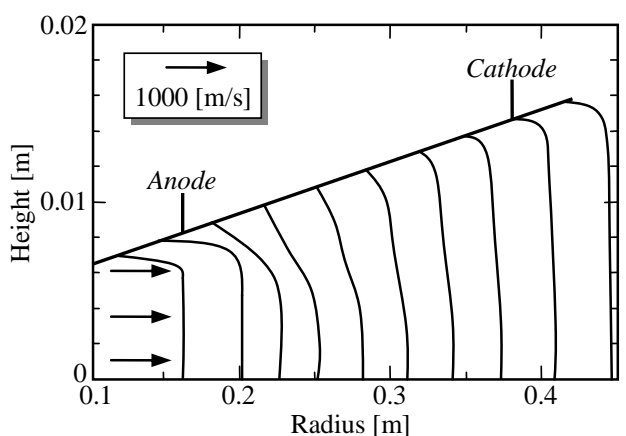

(b) $S=0.5$

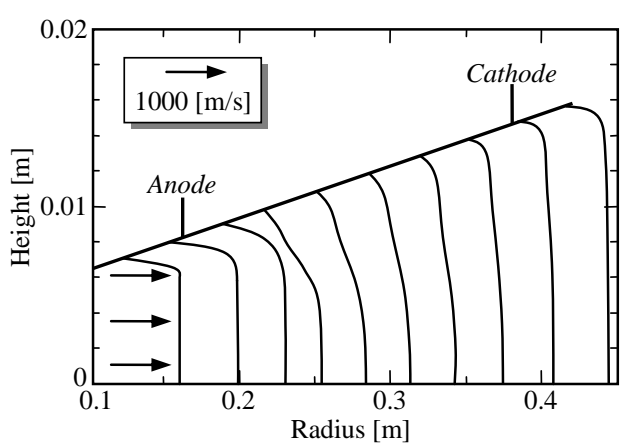

(c) $S=1.0$

Figure 6. Distribution of radial flow velocity with various inlet swirl.

The increase of Hall parameter leads to a substantial decrease $\sigma /\left(1+\beta^{2}\right)$ in electrical conductivity in the circumferential direction, the Faraday current density in Eq. (8) decreases. Therefore, the Lorentz force in the channel inlet is weakened, and a low static pressure, as well as a high Hall parameter, is maintained throughout the channel. From the above results, by the implementation of the inlet swirl, a high Hall 
parameter throughout the channel can be maintained and the increase of enthalpy extraction ratio is clearly shown.

The distribution of the radial and circumferential flow velocity of the disk MHD generator are shown in Figs. 6 and 7. The difference in the radial component of flow velocity due to the swirl is remarkably seen in the channel inlet while it is nearly the same profile in the other areas. Fig. 8 shows the flow separation line for each swirl. The flow separation line is the line that connects the area of $u_{r}=0$. In this case, the fluid flows radially outward in the mainstream from the flow separation line, but the boundary layer inside the flow separation line is exfoliated and the vortex is generated in the flow. For small Lorentz force at the generator inlet, as the swirl is provided, the exfoliation component is moved downstream together with the swirl and that area is also small.

Next, the circumferential direction component is focused on. When the electric current flows from the anode to the cathode in the channel, the direction of Lorentz force $\left(j_{r} \times B\right)$ acting on the working fluid is taken as the negative direction of the circumferential component of the flow velocity. When an inlet swirl is not provided, the radial flow in the nozzle is bent in the negative direction by the Lorentz force in the channel. When focusing on the wall vicinity (dotted line) near the upstream part of the channel, the circumferential component is found to be a positive value. This is because the Hall current flows backwards through the area where the electromotive force is weak inside the boundary layer. Because the Lorentz force acting in the negative direction in the mainstream is stronger than the Lorentz force acting in the positive direction at the wall vicinity, the flow velocity near the wall is dragged in the mainstream and changes to a negative value. When the swirl is provided in the positive direction at the inlet, the unique flow field, where the positive direction flow exists in the negative direction wall vicinity in the mainstream, is specially remarkable.

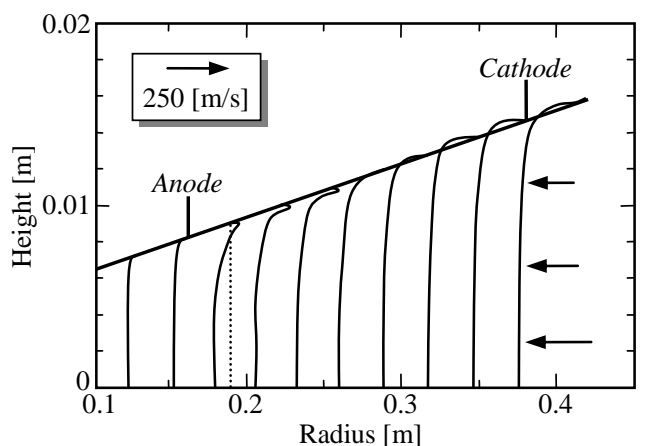

(a) $S=0.0$

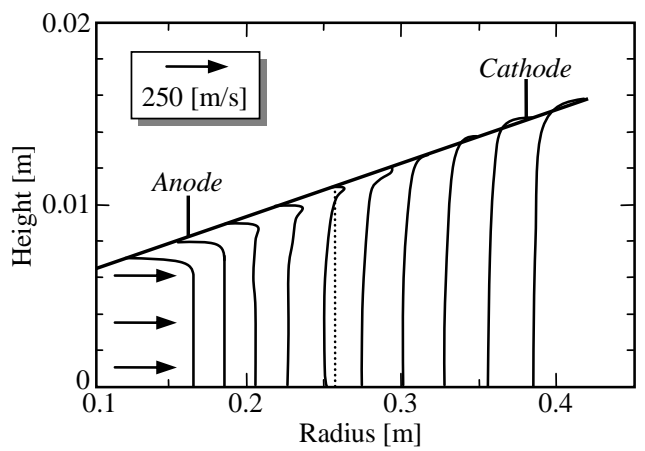

(b) $S=0.5$

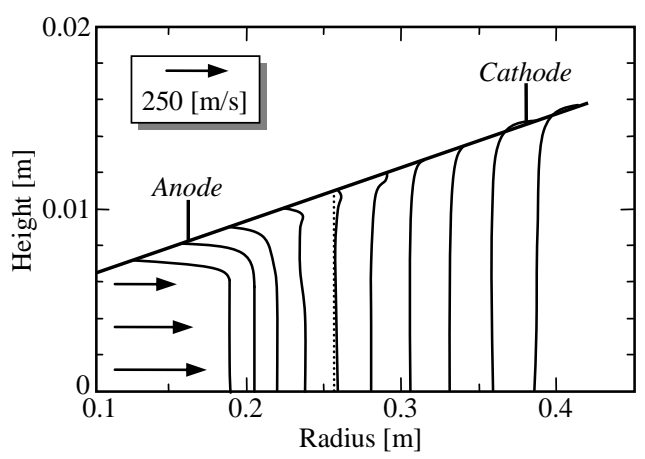

(c) $S=1.0$

Figure 7. Distribution of azimuthal flow velocity with various inlet swirl. 


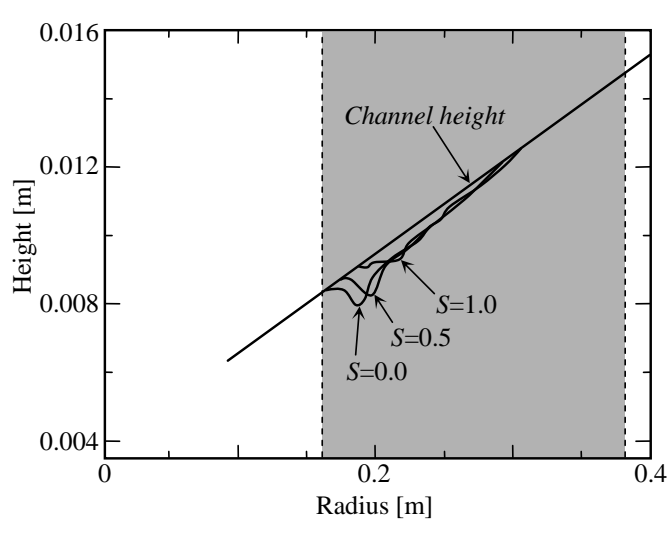

Figure 8. Separation line with various inlet swirl.

In this MHD generator, the Hall parameter is about 8 , the radial flow velocity $u_{r}$ is about 700 $[\mathrm{m} / \mathrm{s}]$, the circumferential flow velocity $u_{\theta}$ is less than $100[\mathrm{~m} / \mathrm{s}]$, and because the electromotive force $u_{\theta} B$ is much smaller than the electromotive force $\beta u_{r} B$, the influence on the power generation performance of such flow field is small.

\section{CONCLUSIONS}

Based on the increase of enthalpy extraction in the disk CCMHD generator, which was shown due to the increase of channel crosssectional area ratio and the implementation of inlet swirl, the enthalpy extraction improvement mechanism was verified using a twodimensional numerical calculation including the boundary layer. As a result, the following is concluded.
(1) By increasing the channel cross-sectional area ratio of the disk MHD generator, the increase of static pressure and the velocity deceleration can be suppressed due to the Lorentz force, and it is possible to maintain a high flow velocity inside the channel and a high Hall parameter. Therefore, both the electromotive force and enthalpy extraction increases. Moreover, the increasing of channel cross-sectional area ratio is not effeted at a high load resistance which acts a large Lorentz force on the fluid because of the large development of boundary layer.

(2) By implementing an inlet swirl, it is possible to maintain a low static pressure inside the channel and the enthalpy extraction ratio rises due to the increase of Hall parameter. If there is a swirl in the flow, the cross-sectional area which is obtained from the flow direction cross-sectional area and the generator channel height is different. As a result, the channel cross-sectional area ratio increases due to the swirl implementation, the static pressure is kept low, and the channel inlet flow velocity increases. This also leads to the increase of enthalpy extraction ratio. The structure of the flow field with the circumferential velocity component which is generated by the Lorentz force and the state of boundary layer inside the channel is also shown. 


\section{Phân tích hoạt động của máy phát điện Từ thuỷ động loại đĩa chu trình kín với ảnh hưởng của các thuộc tính ống dẫn}

\section{- Lê Chí Kiên}

Trường Đại học Sư phạm Kỹ thuật TP.HCM

\section{TÓM TẮT}

Tỉ chiết enthalpy là một trong nhũng thông số quan trọng nhất của máy phát điện Tù thuỷ động loại đĩa chu trình kín. Có hai phuoong pháp cải thiện tỉ chiết enthalpy này là tăng tỉ số mặt cắt ống dẫn và thực hiện dòng chảy xoáy ngõ vào. Bài báo này đã khẳng định co chế cải thiện ti chiết enthalpy bằng nhũng tính toán số hai chiều. Kết quả là việc tăng áp suất tĩnh và sự giảm tốc của dòng chảy có thể được kìm chế bằng lục Lorentz và có thể giũ tốc độ dòng chảy bên

trong ống dẫn và tham số Hall ở giá trị cao. Việc thực hiện dòng xoáy ngõ vào có thể giũ cho áp suất tĩnh thấp bên trong ống dẫn đồng thời tăng tỉ chiết enthalpy do bởi sụ tăng của tham số Hall. Hơn nũa các thông số khác nhu tỉ số mặt cắt ống dẫn sẽ tăng do dòng xoáy ngõ vào, áp suất tĩnh sẽ được giữ ở mức thấp và vận tốc dòng chảy ngõ vào ống dẫn sẽ tăng. Điều này dẫn đến việc tăng ti chiết enthalpy, có nghĩa là tăng công suất điện phát ra.

Tù khóa: Tỉ chiết enthalpy, tỉ số mặt cắt, dòng xoáy ngõ vào, tính toán hai chiều

\section{REFERENCES}

[1]. Ko Kawane, Satoshi Shimada, Jiro Kasahara, Akiko Matsuo, The influence of heat transfer and friction on the impulse of a detonation tube, Combustion and Flame, 158, 10, 2023-2036 (2011).

[2]. Kraig Frederickson, Sergey Leonov, Munetake Nishihara, Evgeny Ivanov, Igor V. Adamovich, Walter R. Lempert, J. William Rich, Energy conversion in high enthalpy flows and non-equilibrium plasmas,
Progress in Aerospace Sciences, 72, 49-65 (2015).

[3]. Mustafa Turkyilmazoglu, MHD fluid flow and heat transfer due to a shrinking rotating disk, Computers \& Fluids, 90, 51-56 (2014).

[4]. Leila Rajaee, Homayoon Eshraghi, Roman O. Popovych, Multi-dimensional quasisimple waves in weakly dissipative flows, Physica D: Nonlinear Phenomena, 237, 3, 405-419 (2008).

[5]. Donghun Park, Seung O. Park, Influence of two-dimensional smooth humps on linear 
and non-linear instability of a supersonic boundary layer, Computers \& Fluids, 79, 140-149 (2013).

[6]. S.E. Aly, Injection effect on two dimensional boundary layer, Energy Conversion and Management, 41, 6, 539-550 (2000).

[7]. Jeremy Gartner, Michael Amitay, Effect of boundary layer thickness on secondary structures in a short inlet curved duct, International Journal of Heat and Fluid Flow, 50, 467-478 (2014).

[8]. Takayuki Watanabe, Masaya Shigeta, Nobuhiko Atsuchi, Two-temperature chemically-non-equilibrium modeling of argon induction plasmas with diatomic gas, International Journal of Heat and Mass Transfer, 49, 25-26, 4867-4876 (2006).

[9]. Seung-Jun Lee, Ik Kyu Park, Jae Jun Jeong, Modified CIP-CSL/FV method for incompressible flows, Computers \& Fluids, 86, 240-250 (2013)

[10]. M. Aoyagi, S. Ito, H. Hashizume, Numerical study of the MHD flow characteristics in a three-surface-multi-layered channel with different inlet conditions, Fusion Engineering and Design, 89, 7-8, 1227-1231 (2014).

[11]. T. Inoue, M. Matsui, H. Takayanagi, K. Komurasaki, Y. Arakawa, Effect of swirl flow on an atmospheric inductively coupled plasma supersonic jet, Vacuum, 80, 11-12, 1174-1178 (2006). 